\title{
Phthalocyanines as an alternative to soluble polymer-supported platforms in organic synthesis
}

\author{
Clifford C. Leznoff* \& Sandra V. Agostino \\ Department of Chemistry, York University, Toronto, Ontario, Canada M3JIP3 \\ (*Author for correspondence, E-mail: leznoff@yorku.ca,Tel: +1-416-736-2100,Fax: +1-416-736-5936)
}

Key words: MALDI-MS analysis, organic synthesis on phthalocyanines, piperazine and piperidine derivatives

\begin{abstract}
Summary
Some small molecules, such as phthalocyanines, capable of exhibiting greatly enhanced capacities and acting as internal tags, are shown to be effective as replacements for polydisperse polyethylene glycols, in soluble polymer-supported type synthesis of some piperidine and piperazine derivatives.
\end{abstract}

Abbreviations: Pc, phthalocyanines; MPEG, polyethylene glycol monomethyl ether; THF, tetrahydrofuran

Since phthalocyanines $[1,2](\mathrm{Pc})$ are inert to many chemical reactions; can be usually selectively precipitated with diethyl ether; have high capacity for organic substrates on a weight by weight basis; and, due to their intense green color, can act as internal colored tags, these molecules would make ideal replacements for soluble polymer-supported platforms $[3,4]$ for organic synthesis. Compared to polyethylene glycol monomethyl ether (MPEG), phthalocyanines have at least 16 times the capacity of MPEG, but still have the advantages inherent in solid phase organic synthesis [5-7].

We now report for the first time the use of a phthalocyanine, a non-polymer molecule, as a soluble support unit. Shey and Sun [8] reported the use of a MeOPEG-OH polymer for complete analysis of a soluble supported reaction where proton NMR determined the extent of the liquidphase reaction without cleavage from the soluble matrix [8]. In our work, treatment of the known 2,9,16,23-tetrakis(2hydroxymethyl-2-methylbutoxy)phthalocyanine [9] (1) with copper acetate gave 2,9,16,23-tetrakis(2-hydroxymethyl-2methylbutoxy)phthalocyaninatocopper(II) ${ }^{1}(2)$ as the soluble support unit (Scheme 1).

Here Pc 2 was used in this test strategy. The Pc support 2 was suspended in a solution of toluene where an excess of 4-chloromethylbenzoyl chloride (3) was added. The reaction mixture was heated for $5 \mathrm{~h}$. At this point, precipitation was easily induced with diethyl ether and washed with ether several times to give the Pc-bound benzyl chloride $4^{1}$. It should be noted that complete precipitation is easily observed when the supernatent liquid is completely devoid of the blue color of the phthalocyanine. The eye can detect less than a $10^{-5} \mathrm{M}$ solution of the Pc. The infrared spectrum of this precipitate exhibited a strong absorption peak at $1718.0 \mathrm{~cm}^{-1}$, indicative of the carbonyl group of the ester and no absorptions were observed in the alcohol region. A MALDI-MS spectrum of this product showed a peak at 1651.0 Da (relative intensity $100 \%$ ), indicating formation of the tetraester. As shown below, however, partial reaction to form the mono, di and triester also occurred. Other ions in the spectrum included peaks at 1540.4 and $1431.4 \mathrm{~m} / \mathrm{z}$, which could not be identified as any molecular structure which could be formed from the reaction (Figure 1).

The Pc-bound benzyl chloride 4 was then dissolved in anhydrous dichloromethane and an excess of piperidine (5) or a 40-fold excess of piperazine (6) was added to this mixture, which was stirred at room temperature for $24 \mathrm{~h}$, to give the Pc bound piperidine 7 and piperazine 8 products, respectively. A very large excess of 6 was employed to ensure that reaction occurred at only one of the amine groups and that no double-bound products would be formed $[10,11]$. These reactions were diluted with ether, and an IR spectrum of the washed precipitates exhibited strong absorptions at 1718 $\mathrm{cm}^{-1}$ for the ester group of $7^{2}$. The Pc-bound piperazine 8 was benzoylated with excess benzoyl chloride in anhydrous DMF and triethylamine at room temperature for $24 \mathrm{~h}$ to give the Pc-bound piperazine amide 9, which in addition to the ester peak showed an absorption peak at $1697 \mathrm{~cm}^{-1}$ due to the amide. 

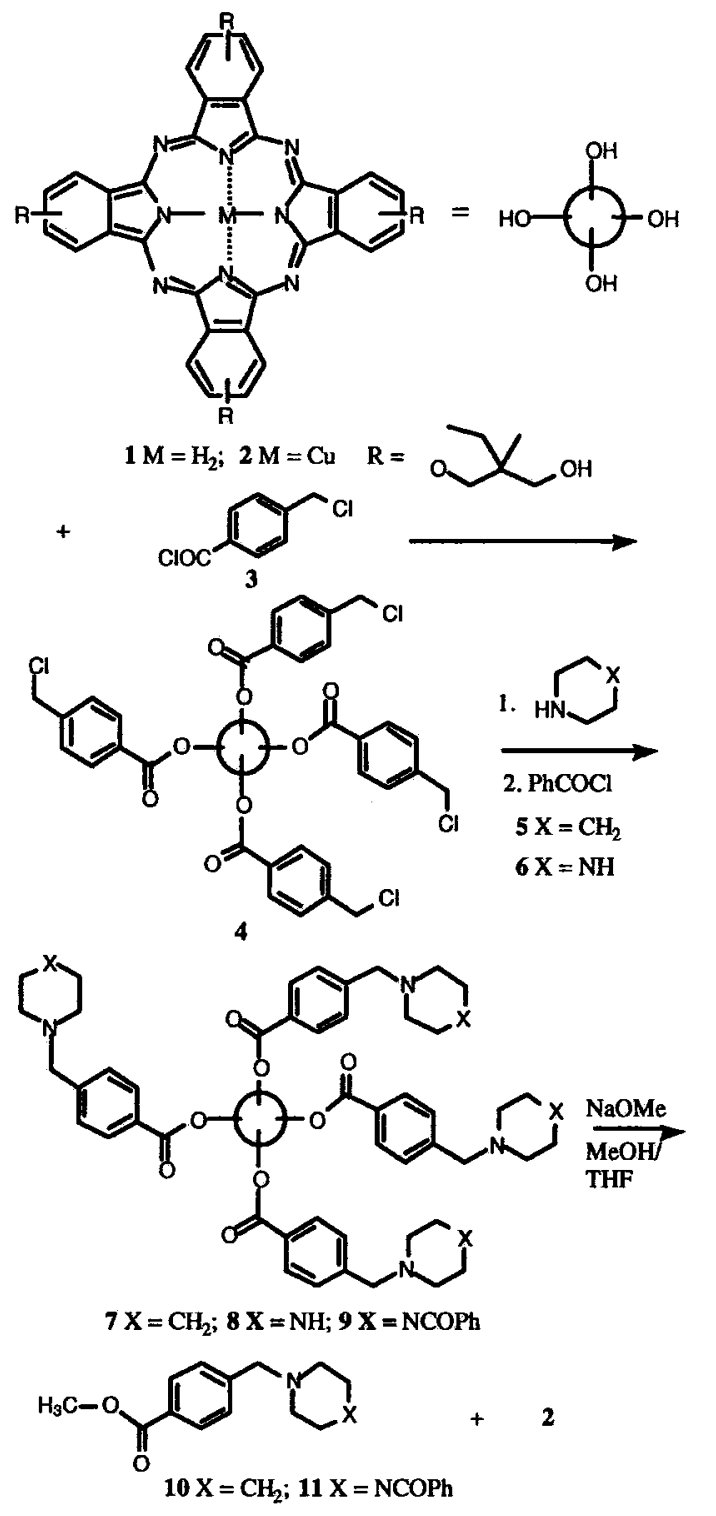

Scheme 1. Phthalocyanine supported synthesis.

A MALDI-MS of the precipitate 7 exhibited molecular ions, which was indicative of Pc 7 being formed. Although partial reaction of starting $\mathrm{Pc} \mathbf{2}$ with $\mathbf{3}$ had not been indicated in the MALDI-MS of 4, the MALDI-MS of the precipitate 7 from the addition of piperidine showed that indeed, these products were present. Thus, analysis of the MALDI-MS spectrum of 7 showed that products derived from the $\mathrm{Pc}$ bound mono, bis, tris and tetrakis benzyl chloride derivatives of 7 were substituted by one $(1241.5 \mathrm{~m} / \mathrm{z})$, two $(1443.5 \mathrm{~m} / \mathrm{z})$, three $(1644.7 \mathrm{~m} / \mathrm{z})$ and four $(1845.8 \mathrm{~m} / \mathrm{z})$ piperidine units. The MALDI-MS spectrum of 9 , formed from piperazine, did exhibit the expected peak at $2266.9 \mathrm{~m} / \mathrm{z}$, derived from tetrakis 4 . The precipitates were soluble in common organic

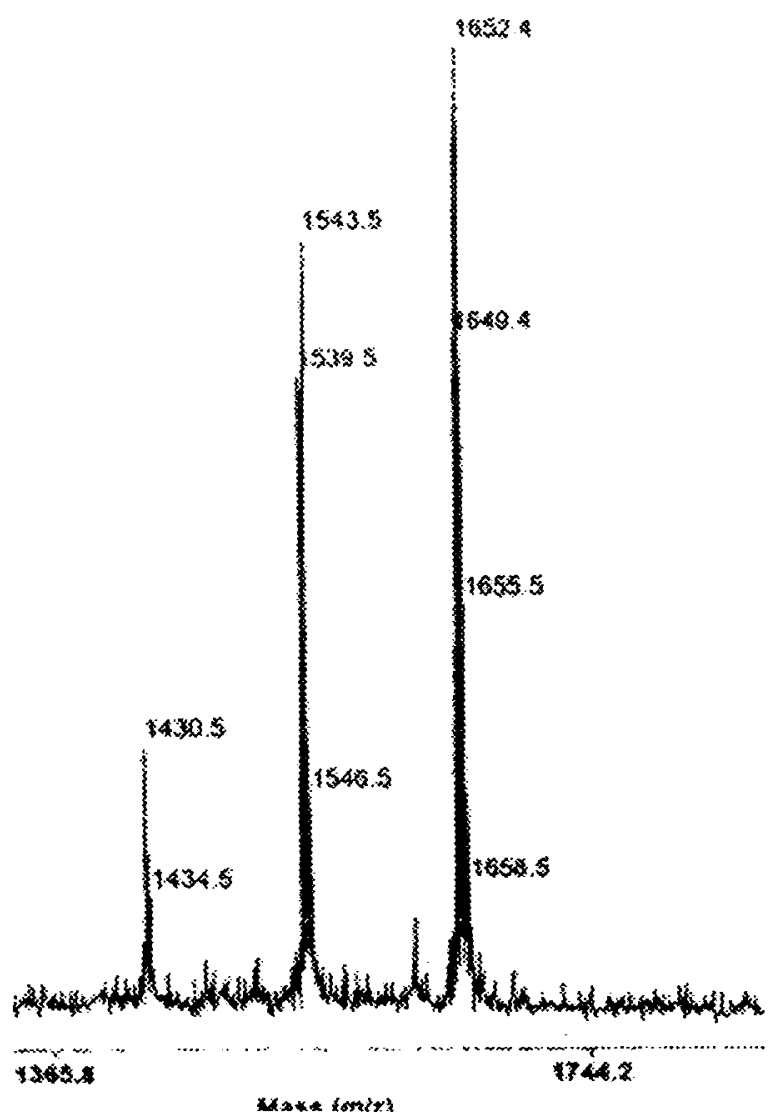

Figure 1. MALDI of 4.

solvents such as: dichloromethane, THF (tetrahydrofuran), toluene, pyridine and remained insoluble in methanol, ether and hexanes.

Final cleavage of the piperidine and piperazine products from the Pc supports 7 and 9 was achieved by transesterification, which most efficiently occurred under reflux conditions with sodium methoxide in a solution of methanol and THF for $12 \mathrm{~h}$. Since in these transesterification cleavage reactions, precipitation of the recovered Pc supports were not induced with ether or hexane, the solvent was removed and the residue was washed with ether to remove any soluble cleavage product from the transesterification. At this stage the recovered phthalocyanine material 2 was not soluble in ether. The ether washings were extracted with water and purified by chromatography with ethyl acetate:hexanes (9:1). From Pc 7 a product 10 was obtained which showed spectroscopic properties consistent with the proposed structure [12]. The final product 10 prepared on the Pc system was obtained in a $42 \%$ yield based on the tetrasubstituted Pc 4. An EI-MS exhibited the molecular ion at $232 \mathrm{~m} / \mathrm{z}$, while other fragments seen due to the loss of OMe $(202 \mathrm{~m} / \mathrm{z})$, and piperidine $(149 \mathrm{~m} / \mathrm{z})$, further confirmed the structure, of this known compound [12]. From Pc 9 the EI-MS obtained of the cleaved known product [12] purified by ethyl acetate:ether $(55: 15)$ gave a parent ion 


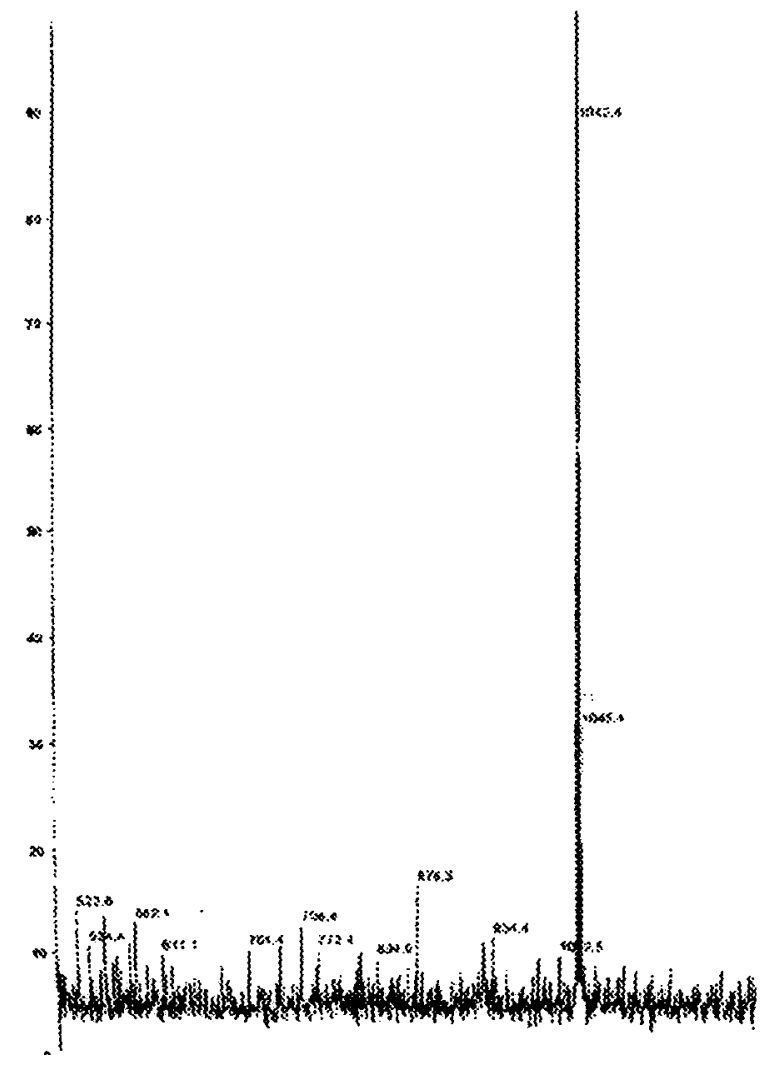

Figure 2. MALDI of recovered 2.

at $338 \mathrm{~m} / \mathrm{z}$, although the yield of $\mathbf{1 1}$ was only about $10 \%$, depending on the loading of 10. An IR-spectrum obtained of the Pc residues of these reactions showed no ester peaks, which were present before the transesterification reaction, thus indicating that the reaction was complete. The Pc obtained from this reaction was washed with water and dried. The MALDIMS of these precipitates indicated that the cleavage was complete giving back the initial Pc 2 (Figure 2).

Although NMR methods were effective for monitoring the synthesis of $\mathbf{1 0}$ and $\mathbf{1 1}$ on MPEG [8], this method was less effective using the Pc system. There are several reasons for this. Firstly, the Pc 2 selected for this proof of concept demonstration was a paramagnetic copper Pc and thus generally unsuited for NMR spectroscopy. Secondly, a tetrasubstituted Pc, such as 2, exists as a mixture of isomers, which complicates the NMR spectra. Thirdly, the fact that four functionalities exist on each Pc platform means that incomplete reactions can further give complex NMR spectra. We, in fact, had initially tried some reactions on the diamagnetic zinc analog of Pc 2, but found that NMR was not too useful as a characterization tool in this system, due to the second and third reasons. On the other hand, MALDI-MS proved to be invaluable in characterizing exactly what was occurring on the phthalocyanine platform, particularly since phthalocyanines usually give good molecular ions.
The MALDI-MS of the precipitated recovered Pc 2 showed the parent ion, but with a slightly different isotopic distribution pattern than that of freshly prepared Pc 2. Recycled 2 was subjected to esterification with $\mathbf{3}$, but the MALDIMS of this product exhibited peaks corresponding to the addition of only one and two units of 3. Optimization of the reesterification step may enable 2 to be recovered and re-used.

In summary, like fluorous tags [13-15] or precipitons [16] which have their own advantages and disadvantages, phthalocyanines have been shown to act as small molecule supports in an organic synthesis. Advantages of this protocol, compared to reactions on MPEG, for example, include increased capacities, visual monitoring of the precipitation process, the use of MALDI-MS in following each step of the reaction, and simple recovery of the support for re-use. One disadvantage includes the fact that NMR was not useful for the described system, but the use of a symmetrical phthalocyanine such as an octasubstituted $\mathrm{Pc}[1,2,17-19]$ may alleviate this problem and is the subject of continuing studies.

\section{Acknowledgements}

The authors are grateful to the Natural Sciences and Engineering Council of Canada for support of this research.

\section{Notes}

1. Preparation of 4: To $51 \mathrm{mg}$ of 1 [9] in a mixture of 2-methoxyethanol: toluene (1:2) was added copper(II) acetate $(21 \mathrm{mg})$. The reaction mixture was stirred at $130^{\circ} \mathrm{C}$ for $30 \mathrm{~h}$. At this time, the solvent was evaporated and the residue washed with water repeatedly and dried. The crude product was further purified by silica gel flash chromatography with THF:hexanes (3:2) to yield $48.2 \mathrm{mg}(89 \%)$ of $2: \mathrm{mp}>300{ }^{\circ} \mathrm{C}$; UVVIS (toluene) $\lambda_{\max } / \mathrm{nm}(\log \varepsilon$ ) 678 (3.6), 334 (3.2); MALDI-MS for $\mathrm{C}_{56} \mathrm{H}_{64} \mathrm{~N}_{8} \mathrm{O}_{8} \mathrm{Cu} m / 2$ (relative intensity, \%) $1040.3(\mathrm{M}+, 100)$; Anal Caled. for $\mathrm{C}_{56} \mathrm{H}_{64} \mathrm{~N}_{8} \mathrm{O}_{8} \mathrm{Cu}$ : C, 64.63; H, 6.63; N, 10.77. Found: $\mathrm{C}$, $64.32 ; \mathrm{H}, 6.32 ; \mathrm{N}, 10.56 \%$

To a suspension of $2(52.2 \mathrm{mg})$ in $5 \mathrm{ml}$ of anhydrous toluene was added 4-chloromethylbenzoyl chloride (3) $(76.1 \mathrm{mg})$. The reaction was heated at reflux for $5 \mathrm{~h}$. The reaction was then diluted with ether and centrifuged. The precipitated Pc 4 was washed with ether three times, once with water and finally dried to yield $63 \mathrm{mg}(76 \%)$ of $4 . \mathrm{IR} \nu / \mathrm{cm}^{-1}(\mathrm{KBr})$ $2967-2881(\mathrm{~m}), 1718(\mathrm{vs})(\mathrm{C}=\mathrm{O}), 1607 \mathrm{~cm}^{-1}$ (s) $(\mathrm{C}=\mathrm{C})$; MALDI-MS $m / z 1651.4\left(\mathrm{C}_{88} \mathrm{H}_{84} \mathrm{~N}_{8} \mathrm{O}_{12} \mathrm{Cl}_{4} \mathrm{Cu}^{+}\right)$.

2. Preparation of 7 : In a typical Pc-supported reaction, a suspension of 4 (20.3 $\mathrm{mg}$ ) in anhydrous dichloromethane was treated with piperidine (5) $(0.05 \mathrm{ml})$ and the reaction mixture was stirred at room temperafure for $24 \mathrm{~h}$. Diethyl ether was added until all the phthalocyanine material had precipitated as indicated by the colourless supernatent liquid. The blue-green precipitate was washed with ether three times, once with water, once with methanol and dried to yield $19.7 \mathrm{mg}(87 \%)$ of 7: IR $v / \mathrm{cm}^{-1}$ (KBr) 2931-2791 (m), 1720 (s), 1608 (s); MALDI-MS $m / z: 1241.5\left(\mathrm{C}_{69} \mathrm{H}_{79} \mathrm{~N}_{9} \mathrm{O}_{9} \mathrm{Cu}\right)^{+}, 1443.5\left(\mathrm{C}_{82} \mathrm{H}_{94} \mathrm{~N}_{10} \mathrm{O}_{10} \mathrm{Cu}\right)^{+}, 1644.7$ $\left(\mathrm{C}_{95} \mathrm{H}_{109} \mathrm{~N}_{11} \mathrm{O}_{11} \mathrm{Cu}\right)^{+}, 1845.8\left(\mathrm{C}_{108} \mathrm{H}_{124} \mathrm{~N}_{12} \mathrm{O}_{12} \mathrm{Cu}\right)^{+}$

\section{References}

1. Leznoff, C.C. and Lever, A.B.P. (Eds.) Phthalocyanines: Properties and Applications, vol. 1-4, VCH, New York, 1989, 1992, 1993, 1996. 
2. McKeown, N.B., Phthalocyanine Materials: Synthesis, Structure and Function, Cambridge University Press, New York, 1998.

3. Toy, P.H. and Janda, K.D., Soluble polymer-supported organic synthesis, Acc. Chem. Res., 33 (2000) 546-554.

4. Haag, R., Dendrimers and hyperbranched polymers as high loading supports for organic synthesis, Chem. Eur. J., 7 (2001) $327-$ 335.

5. Leznoff, C.C., The use of insoluble polymer supports in general organic synthesis, Acc. Chem. Res., 11 (1978) 327-333.

6. Früchtel, J.S. and Jung J., Organic chemistry on solid supports, Angew. Chem. Int. Ed. Engl., 35 (1996) 17-42.

7. Ellman, J.A., Design, synthesis and evaluation of small-molecule libraries, Acc. Chem. Res., 29 (1996) 132-143.

8. Shey, J.Y. and Sun, C.M., Liquid-phase combinatorial monitoring by conventional ' $H$ NMR spectroscopy, Tetrahedron Lett., 43 (2002) 1725-1729.

9. Leznoff, C.C., Svirskaya, P.I., Khouw, B. Cerny, R.L., Seymour P. and Lever, A.B.P., The syntheses of monometallated and unsymmetrically substituted binuclear phthalocyanines and pentanuclear phthalocyanine by solution and polymer support methods, J. Org. Chem., 56 (1991) 82-90.

10. Dixit, D.M. and Leznoff, C.C., Insoluble supports as monoblocking agents of symmetrical diamines, J. Chem. Soc. Chem. Commun. (1977) $798-799$.
11. Dixit, D.M. and Leznoff, C.C., The synthesis of unsymmetrical diamines and monoamide monotosylamides from symmetrical diamines. Isr. J. Chem., 17 (1978) 248-252.

12. Shey, J.Y. and Sun, C.M., Liquid phase combinatorial synthesis of benzyl piperazines, Bioorg. Med. Chem. Lett., 9 (2001) 519-522.

13. Horvath, I.T., Fluorous Biphase Chemistry, Acc. Chem. Res., 31 (1998) 641-650.

14. Curran, D.P., Strategy-level separations in organic synthesis: From planning to practice, Angew. Chem. Int. Ed. Engl., 37 (1998) 1174 1196.

15. Hein, J.E. and Hultin, P.G., Asymmetric aldol reactions using a fluorous oxazolidinone chiral auxiliary, Synlett, 5 (2003) 635-638.

16. Bosanac, T., Yang, J. and Wilcox, C.S., Precipitons-functional protecting groups to facilitate product separation: Applications in isoxazoline synthesis, Angew. Chem. Int. Ed. Engl., 40 (2001) 1875-1879.

17. Maya, E.M., Garcia, C., Garcia-Frutos, E.M., Vazquez, P. and Torres, T., Synthesis of novel push-pull unsymmetrically substituted alkynyl phthalocyanines, J. Org. Chem., 65 (2000) 2733-2739.

18. Cook, M.J., McMurdo, J. and Powell, A.K., X-ray crystal structure of $1,4,8,11,15,18,22,25$-octa-iso-pentyloxyphthalocyanine, J. Chem. Soc. Chem. Commun. (1993) 903-904.

19. Henari, F., Davey, A., Blau, W., Haisch, P. and Hanack, M., The electronic and non-linear optical properties of oxo-titanium phthalocyanines, J. Porphyrins Phthalocyanines, 3 (1999) 331-338. 